\title{
Make Way: An Intelligent Real-Time Traffic Light Control System
}

\author{
Mouleeshu Warapprabu R., Niviya Dharshini S., Pearlstone Emmanuel G., Sathish K.M., \\ Yashar Arafath M.
}

\begin{abstract}
Nowadays, automatic traffic light control is becoming an important requirement for travelers and number of road users especially for emergency service providers such as ambulance drivers, fire fighters etc... Various alternatives have been proposed, but it has certain limitations. One such example is using an RF transmitter mounted on the ambulance which will communicate with the $R F$ receiver mounted on the signal post in the traffic control system. A special algorithm is provided to control the traffic signals automatically by pressing the key provided in the keybord on the ambulance by the driver.But in this case, there is big trouble for car accidents or road accidents, because of automatic adjustment and a large number of vehicles, and there is a problem of delay in first aid service, with these overcrowded roads. This paper describes a solution that is "Intelligent Ambulance with Automatic Traffic Control" which includes the accident detecting, alerting and tracking mechanism with an automatic traffic light controlling system to overcome this delay of first aid service. An ambulance can thereby easily finde a freeway to reach the victim in a minimal time and thereby providing first aid as soon as possible. This is possible by using an $R F$ transmitter on the ambulance which will communicate with the $R F$ receiver mounted on the signal post in the traffic control system. To control the traffic signals automatically, and to move towards the location in minimal time, a specific algorithm is proposed in this paper. Thus, the traffic light gets controlled by the intelligent ambulance itself, in such a way that it could provide free path to the ambulance[1].
\end{abstract}

Keywords: Arduino, $R F$ transmitter, $R F$ receiver.

\section{INTRODUCTION}

Nowadays, increased population and luxurious living lead to an increase in the traffic on public roads. In such bustling situation people are least cared abount human life. One great backlog is that people doent bother about calling an emergency unit in case of an accident. Moreover, it becomes extremely difficult to provide way for ambulances due to heavy traffic which leads to delayed first aid and in certain cases loss of lives. In order to overcome their negative factors and to provide first aid to the victim, this system - "Automatic traffic control for an ambulance" is proposed in this paper.

Revised Manuscript Received on December 30, 2019.

Mouleeshu warapprabu R., Department of Electronics and Instrumentation Engineering, Kongu Engineering College, Perundurai638060.

Niviya Dharshini S., Department of Electronics and Instrumentation Engineering, Kongu Engineering College, Perundurai-638060.

Pearlstone Emmanuel G., Department of Electronics and Instrumentation Engineering. Kongu Engineering College, Perundurai-638060.

Sathish K.M., Department of Electronics and Instrumentation Engineering, Kongu Engineering College, Perundurai-638060.

Yashar Arafath M., Department of Electronics and Instrumentation Engineering, Kongu Engineering College, Perundurai-638060.

(c) The Authors. Published by Blue Eyes Intelligence Engineering and Sciences Publication (BEIESP). This is an open access article under the CC BY-NC-ND license (http://creativecommons.org/licenses/by-nc-nd/4.0/)
* Correspondence Author

This paper describes the alternative in case of traffic on emergency situation such as, taking the patient to the hospital in order to free or release the traffic. This intelligent ambulance controls the traffic light itself such that the traffic light converts in a manner so that it could receive the freeway to the hospital.[2]

Ongoing through the detailed study on the literature it is proposed to develop a system that acquires data from RF transmitter and transmits it to the RF receiver.

The prototype proposed here replacesthecurrenttraffic light systemandgives complete details about the ambulance with high accuracy.Adopted ideologies in the development of traffic light control from the expertise kinds of literature are discussed as follows

The first traffic light system designed by Levi L. Rose (1990), used only for an emergency vehicle where the Emergency vehicle transmits signal from the installed sensor to the traffic light intersection where the receiver is placed [3].

The traffic light system designed by M. R. Smith (2004), described the system which warns the people thereby providing an easy way to emergency vehicle.[4].

The traffic light system designed by Salim Bin Islam (2005), provided aalternative by considering the density of traffic and thereby controlling the traffic using a micro controller [5].

Before the invention of Ardunio, the PIC Microcontroller board was introduced by general instruments was one of the most used tools for electronic enthusiasts. Due to its ease of working through the programming language including PBASIC, the PIC microcontroller board is most preferred for its speed.

W. L. Mitchell (2006), provided a measure that provides route for emergency vehicles thereby overcoming the traffic problem [1].

W. E. Brill (2006), has designed a system to alert the driver of an approaching emergency vehicle by producing a sound signal from the equipment mounted on an emergency vehicle, a sound signal detection unit and a display unit remotely located on the non-emergency vehicle[2].

This system consists of main components that play a vital role in the transmission and reception of signals. They are discussed below

\section{Encoder}

An entity or device which will encode information in several ways such as compressing, converting or securing it into a different format is known as Encoder.

\section{Decoder}

Decoder puts back together all the pieces of data up which are essentially scrambled into pieces by the encoding process. 


\section{Rf Transmitter and Receiver Module}

$\mathrm{RF}$ Transmitter and receiver module is used in this proposed work to implement wireless communication.

\section{SMPS (Switched Mode Power Supply)}

Switched Mode Power Supply (SMPS) is the most following method for DC power supply in a modern system, mainly for its capability to handle fluctuating loads. This is becoming a great area of concern, apart from the efficiency of the size and weight of the power supplies.[1] A list of RF ranges with different frequency rates are tabulated in Table 1.1

Table 1.1 RF Frequency Ranges .[2]

\begin{tabular}{|c|c|c|}
\hline Designation & Frequencies & Wavelengths \\
\hline $\begin{array}{c}\text { Very Low } \\
\text { Frequency }\end{array}$ & $3 \mathrm{kHz}-30 \mathrm{kHz}$ & $(100-10) \mathrm{km}$ \\
\hline $\begin{array}{c}\text { Low Frequency } \\
\text { Medium } \\
\text { Frequency }\end{array}$ & $\begin{array}{c}300 \mathrm{kHz}-300 \\
\mathrm{kHz}\end{array}$ & $(10-1) \mathrm{km}$ \\
\hline $\begin{array}{c}\mathrm{MHz} \\
\text { High Frequency }\end{array}$ & $\begin{array}{c}3 \mathrm{MHz}-30 \\
\mathrm{MHz}\end{array}$ & $(1-100) \mathrm{m}$ \\
\hline
\end{tabular}

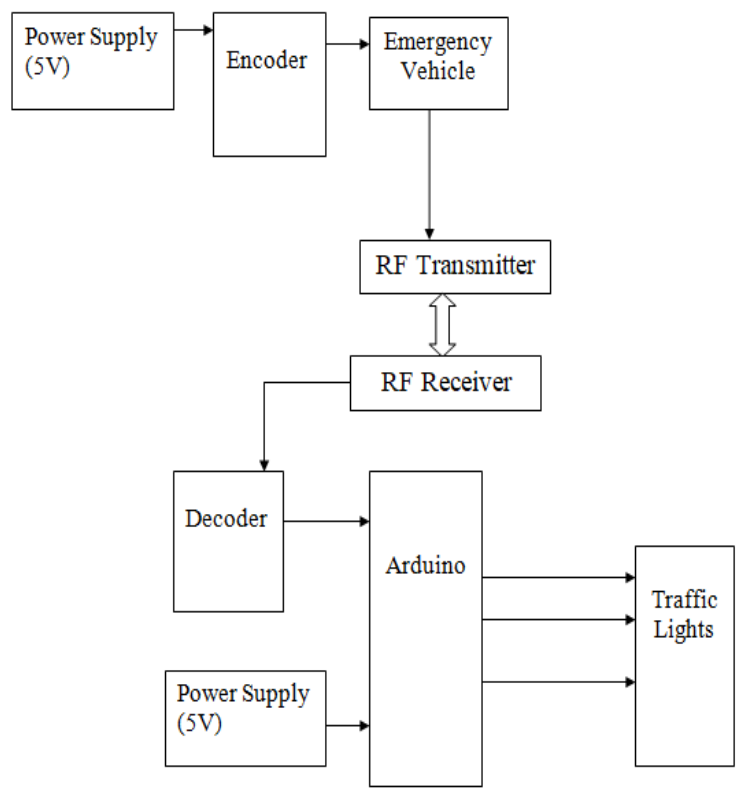

Figure 1. Block Diagram of Traffic Controlling System for Emergency Vehicle

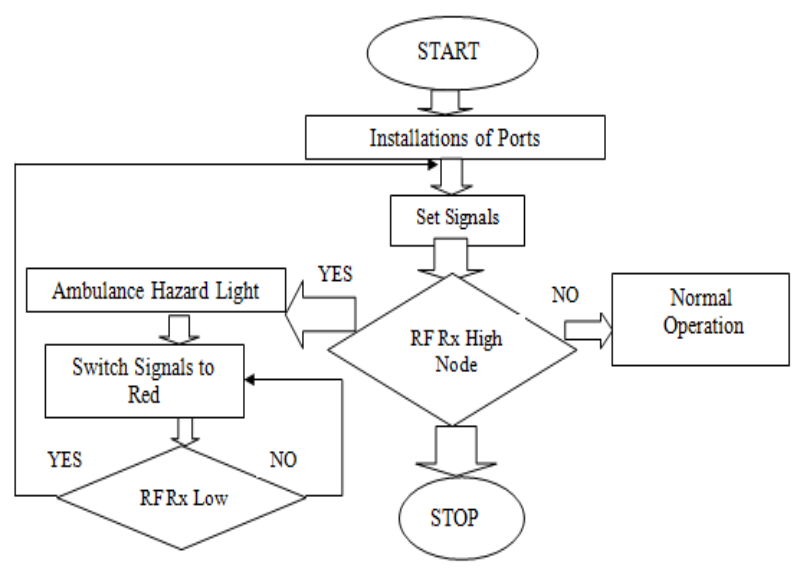

Figure 2. Process Flow of Traffic Control System

\section{II.METHODOLOGY}

The basic diagram shown in figure 2 is that the general arrangement of the components or parts of a complex system or method, such as industrial equipment or an electronic circuit. Figure 3 depicts the method concerned in traffic light management which has acquisition, analyzing and signal processing that is explained below.

\section{A. Data Acquisition:}

The first step of the project is to transmit the signal from the motorcar. It ought to be simply actuated by the driver who is driving the passenger to the hospital that the transmitter trigger switch is connected on to the siren switch. Therefore whenever the driver activates the siren, it'll mechanically trigger the transmitter. Once the transmitter is triggered it'll begin transmission $434 \mathrm{MHz}$ signals. The transmitter is supplied with an encoder IC. Encoders are digital ICs used for encoding. An Encoder IC usually consists of an enable pin that is typically set high to point the operation. It consists of $2^{\wedge} n$ input lines and $n$ output lines with every input line being drawn by a code of zeros and ones that are mirrored at the output lines. The encoder starts operating with a low signal on the TE pin. When a low signal is received, the HT12E starts transmission 4 bits of data ceaselessly. And also the output cycle repeat based on the status of the TE pin in the Encoder IC. If the TE pin retains the low signal the cycle repeats as long because the low signal within the TE pin exists. The encoder IC is going to be in standby mode if the TE pin is disabled and so the status of this pin was necessary for the encoding process. The address of these bits can be set through A $0-$ A7 and also the same scheme ought to be employed in decoders to retrieve the signal bits.

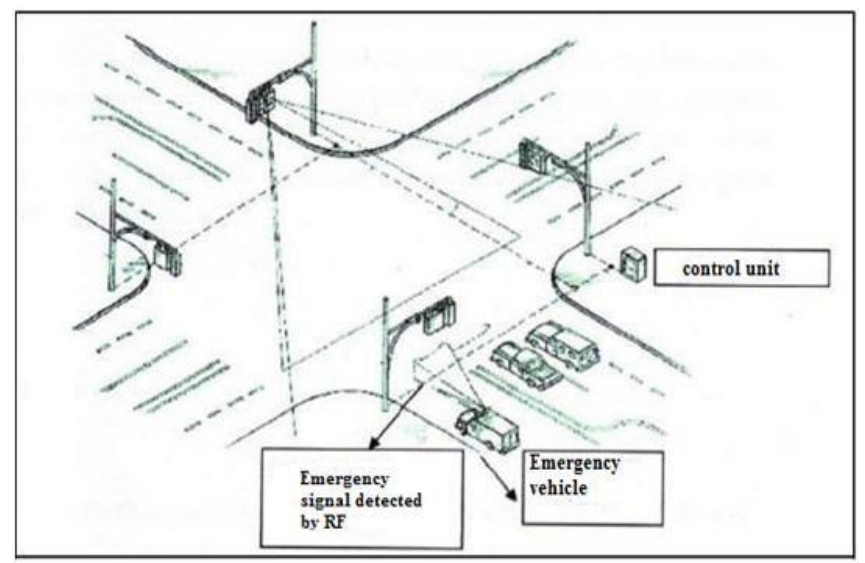

Figure 3. Proposed System of Make Way

\section{B. Analyzing:}

This model utilizes the RF module (Tx/Rx) which is employed to drive output from a faraway place. The RF module uses radio frequency to send signals. These signals are transmitted at a specific frequency and a baud rate based on the necessity. The corresponding frequency range varies from $30 \mathrm{kHz}$ to $300 \mathrm{GHz}$. In the RF system, the digital data that is transmitted is drawn because of the variations within the amplitude of the radio wave. This sort of modulation used here is thought of as Amplitude Shift Keying (ASK). 
Transmission through Radio Frequency is best than Infrared as a result of several reasons. Signals through RF will travel larger distances by creating it appropriate for long-range applications. Whereas IR is generally operated in line-ofsight mode, RF signals will travel even once there's an obstruction between transmitter \& receiver. Next, RF is a lot of robust and reliable for transmission. RF communication uses a specific frequency for applications. The transmitter/receiver $(\mathrm{Tx} / \mathrm{Rx})$ pair operates at a frequency of $434 \mathrm{MHz}$. The RF transmitter receives serial data and transmits it wirelessly through RF through its antenna connected at pin4. The parallel to serial data conversion is finished the Encoder. The transmission rate is of $1 \mathrm{Kbps}$ $10 \mathrm{Kbps}$. The transmitted data is received by an $\mathrm{RF}$ receiver in operation at a constant frequency as that of the transmitter and it's decoded. The RF module is usually used alongside a pair of encoder and decoder. HT12E-HT12D, HT640HT648, etc. are some commonly used encoder and decoder pair ICs for various applications [3].

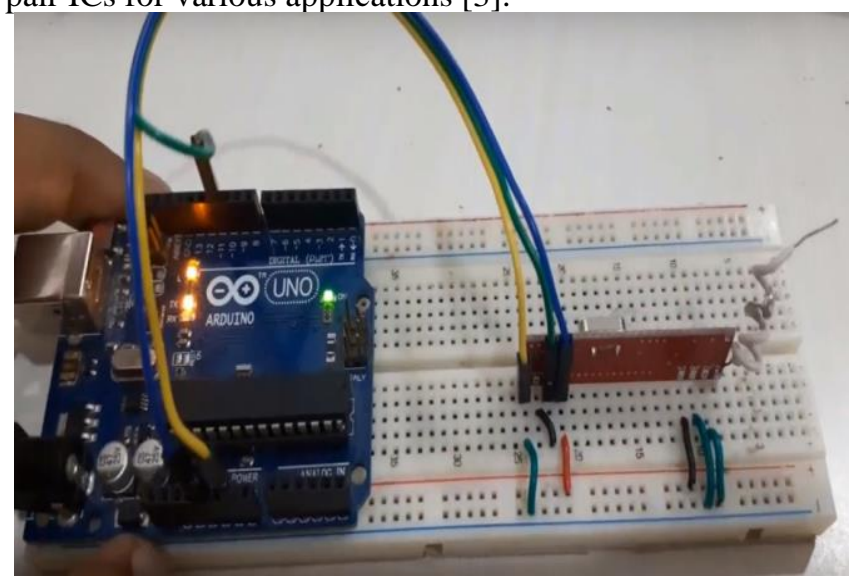

Figure 4. RF Transmitter with Arduino

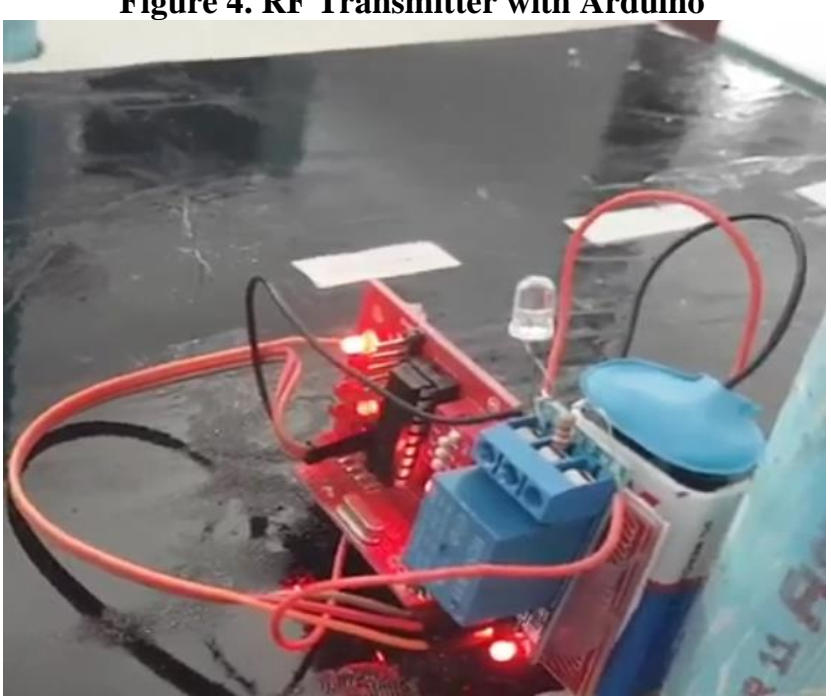

Figure 5. RF Receiver with Arduino

\section{III.RESULTS AND DISCUSSION}

The system working has successfully designed and verified from the truth table given below considering the ambulance is arriving in the first lane. The indication was provided with the help of triggered emergency hazard light in the signal poles, for indicating about the ambulance arriving lane. The remaining signals were at a low state which indicates the red light in the traffic signal. The prototype of the proposed model uses the frequency $434 \mathrm{MHz}$ which will fall under the frequency margin of $3 \mathrm{kHz}$ to $300 \mathrm{GHz}$. The output describes that the desired objectives has been attained. We managed to control an emergency vehicle at distances $100 \mathrm{~m}$ to $1 \mathrm{~km}$ based on the densities of traffic in the different cities far from the traffic signal.Based on the datasheet from the RF frequency range we have been able to achieve the prototype by using RF of suitable frequency[4]. The normal traffic light sequence is shown in table 2 given below.

Table 2. Normal Traffic Light Sequence (Note: A-red; B-amber; C-green)

\begin{tabular}{|c|c|c|}
\hline $\begin{array}{l}\text { TIMELINE } \\
\text { (SECONDS) }\end{array}$ & LANE 1 & LANE 2 \\
\hline 1 & C & A \\
\hline 2 & $\mathrm{C}$ & A \\
\hline 3 & $\mathrm{C}$ & A \\
\hline 4 & $\mathrm{C}$ & $\mathrm{A}$ \\
\hline 5 & $\mathrm{C}$ & A \\
\hline 6 & $\mathrm{C}$ & A \\
\hline 7 & $\mathrm{C}$ & A \\
\hline 8 & $\mathrm{C}$ & A \\
\hline 9 & $\mathrm{C}$ & A \\
\hline 10 & $\mathrm{C}$ & A \\
\hline 11 & $\mathrm{C}$ & A \\
\hline 12 & $\mathrm{~B}$ & A \\
\hline 13 & B & A \\
\hline 14 & $\mathrm{~B}$ & A \\
\hline 15 & A & A \\
\hline 16 & A & A \\
\hline 17 & A & $\mathrm{C}$ \\
\hline 18 & A & $\mathrm{C}$ \\
\hline 19 & A & $\mathrm{C}$ \\
\hline 20 & A & $\mathrm{C}$ \\
\hline 21 & A & B \\
\hline 22 & A & B \\
\hline 23 & A & B \\
\hline 24 & A & A \\
\hline 25 & A & A \\
\hline
\end{tabular}

\section{UNPREDICTEDERROR}

As we are using a wireless mode of communication which is RF, we have faced some unpredicted losses due to different factors.

\section{FACTORS INFLUENCING RF MODULE COMMUNICATION}

The following factors influence the communication of RF Module :

i. One of the major issue is the power transmission. The transmission in the total popwer that comes from the antenna of radio frequency module, usually measured in watts.

ii. The sensitivity of the receiver deals with the minimal demodulation of the receiver signal.

The proposed system gives the traffic light sequence at the time of arrival of an emergency vehicle which is shown in table 3 .

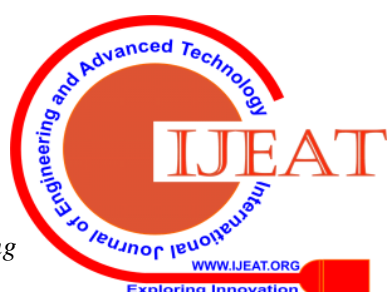




\section{RF INTERFERENCE CAUSES}

i. Spectrum Concentration in various devices

ii. Connection of electronic devices in a compressed manner

iii. Design such that it provides low absorption loss.

\section{TO MINIMIZE RF INTERFERENCE}

\subsection{SHIELDING}

RF shield is mainly used to protect the circuit board in various electronic devices and also to prevent the emissions. This method is one of the best ways to minimize the noise and to increase the wavelength of the received frequency. initially the frequency range is filtered and effective interference can be achieved using this shielding[5].

The proposed system will be developed using Zigbee which may increase the accuracy as shown in figure 3.

Table 3. Traffic Light Sequence in the Proposed System

\begin{tabular}{|c|c|c|c|c|}
\hline $\begin{array}{c}\text { LED's } \\
\text { /LANE } \\
\text { NUMBER }\end{array}$ & LANE1 & LANE2 & LANE3 & LANE4 \\
\hline RED & 0 & 1 & 1 & 1 \\
\hline YELLOW & 0 & 0 & 0 & 0 \\
\hline GREEN & 1 & 0 & 0 & 0 \\
\hline
\end{tabular}

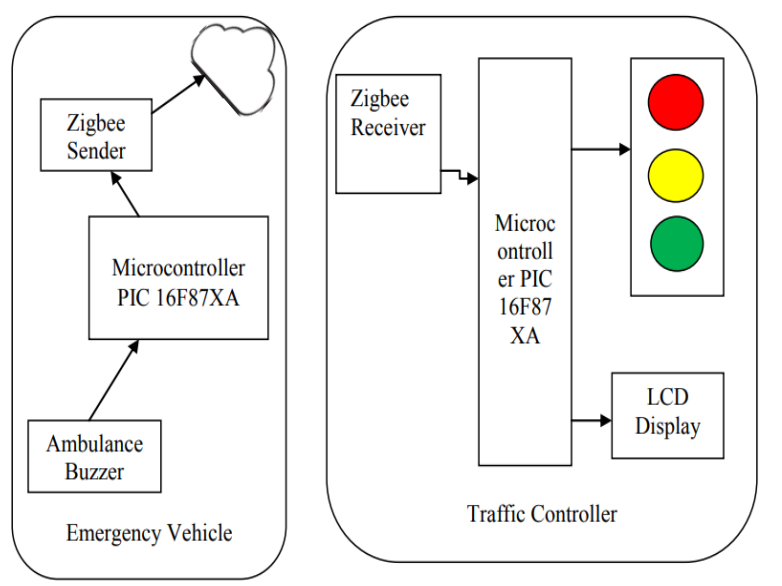

Figure 6. Efficient Way of Traffic Control System

\section{IV.CONCLUSION AND FUTURE SCOPE}

Thus the main objective of the projects which were stated earlier includesimplementation of the Radio Frequency (RF) transmission in the traffic light control for emergency vehicles. The proposed workmakes use of the frequency ranging $434 \mathrm{MHz}$ which comes under Very Low Frequency Range.. Besides, the functionality of the project has successfully cleared the objectives which are the design of an emergency sequence mode of the traffic light. This also satisfies the objective which is the intersection of traffic and changing the sequence back to normal without causing any disturbance to both the pedestrians and the vehicles in traffic. The prototype sequence of this project was developed with the help of an Arduino. In the future, the prototype is going to be implemented in real-life traffic scenarios for testing various difficulties faced and to study the transmission length and reception issues. In real-time, the prototype along with LoRa transceivers can be used for long-range communication without any hindrance and with high accuracy.

\section{ACKNOWLEDGMENT}

We extend our sincere gratitude to our beloved guide Mr. R. Mouleeshu Warapprabum E., Assistant Professor, Department of Electronics and Instrumentation Engineering for her ideas and suggestions, which have been very helpful to complete the project.

\section{REFERENCE}

1. Abubakr S.E., Halla O.A., Tahani A.A (2013) 'A GPS based traffic light pre-emption control system for emergency vehicles' - IEEE International Conference on Computing, Electrical and Electronics Engineering; Khartoum, Sudan. vol.32 pp. 724-729

2. Abu-Mahfouz A.M., Hancke G.P.(2011) 'Extension to Simulate Localization Systems in Wireless Sensor Networks' - IEEE African 2011; Livingstone, Zambia.

3. Bharadwaj R., Deepak J., Baranitharam M., Vaidehi V.V. (2013) 'Efficient dynamic traffic control system using wireless senso networks'- IEEE International Conference on Recent Trends in Information Technology (ICRTIT); Chennai, India.vol.27 pp. 668673.

4. Fan K., Chen J., Cao Q (2013)'Design and research on traffic of wireless sensor network based on LabVIEW' - 2nd International Symposium on Computer, Communication, Control and Automation (3CA 2013); Singapore. pp. 6-9.

5. Uddin S.M., Das K.A., Taleb A.M (2015) 'Real-time area based traffic density estimation by image processing for traffic signal control' - IEEE International Conference on Electrical Engineering and Information Communication Technology (ICEEICT); Dhaka, Bangladesh. vol.42 no.5 pp.1-5.

\section{AUTHORS PROFILE}
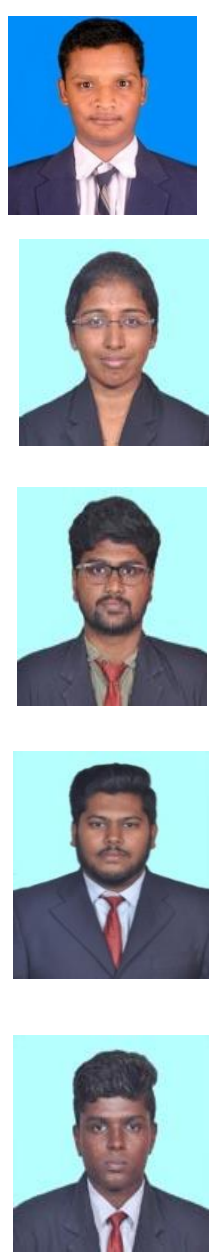

Mouleeshu Warapprabu R., currentlyworking as Assistant Professor in the Department of Electronics and Instrumentation Engineering, Kongu Engineering College, Perundurai,Erode.Hisareaofinterestincludes Signal Processingand Control System. He has published 11 research papers in journals and

Niviya Dharshini S., pursuing his under-graduation degree in the stream of Electronics and Instrumentation Engineering at Kongu Engineering College, Perundurai, Erode. Her areas of interest are Signal Processing and Industrial Automation. She has published a research article in an international journal.

Pearlstone Emmanuel G., pursuing his under graduation degree in the stream of Electronics and Instrumentation Engineering at Kongu Engineering College, Perundurai, Erode. His areas of interest are Data structures and Control Systems. He has published a research article in an international journal.

Yashar Arafath M., pursuing his under graduation degree in the stream of Electronics and Instrumentation Engineering at Kongu Engineering College, Perundurai, Erode. His areas of interest are Industrial Instrumentation and Network Signals and System. He has published a research article in an international journal.

Sathish K. M., pursuing his under graduation degree in the stream of Electronics and Instrumentation Engineering at Kongu Engineering College, Perundurai, Erode. His areas of interest are Embedded Controls and Control systems. 